\title{
OS INVESTIMENTOS PÚBLICOS EM ÁREAS VERDES E A PRODUÇÃO DO ESPAÇO URBANO EM CAMPOS DOS GOYTACAZES/RJ
}

\author{
PUBLIC INVESTMENTS IN GREEN AREAS AND URBAN SPACE \\ PRODUCTION IN THE MUNICIPALITY OF CAMPOS DOS \\ GOYTACAZES, RIO DE JANEIRO STATE, BRAZIL
}

Resumo: A presença de áreas verdes no espaço urbano é um fator que vem contribuindo para a valorização do solo em algumas cidades brasileiras. A partir dos discursos da qualidade ambiental e da sustentabilidade, a "natureza" é evidenciada, e seus atributos são colocados como indicadores irrefutáveis para a melhora da qualidade de vida. 0 objetivo deste trabalho é analisar os investimentos públicos em áreas verdes no município de Campos dos Goytacazes/ RJ, assim como identificar a presença desses espaços na malha urbana no distrito-sede do referido município. Para a estruturação metodológica da pesquisa, além da bibliografia especializada no tema, realizou-se pesquisa documental no Diário Oficial do município, entrevistas semiestruturadas com gestores municipais e levantamento de dados em trabalho de campo. Entre os resultados, pode-se constatar a escassez de áreas verdes em Campos, e que a maioria dessas áreas se localiza nos bairros de maior renda, o que favorece a população de alto status socioeconômico. Foi constatado, também, que o poder público não vem priorizando a criação desses espaços frente às novas dinâmicas socioeconômicas, pois estas se encontram insuficientes na cidade.

Palavras-Chave: Áreas Verdes; Investimentos Públicos; Segregação Socioespacial.
Abstract: Green areas in urban space are a factor that has been contributing to the land valuation in some Brazilian cities. On the basis of the discussions on environmental quality and sustainability, "nature" is evidenced, and its attributes are seen as irrefutable indicators for enhancing the quality of life. The purpose of this work is to analyze public investments in green areas in the municipality of Campos dos Goytacazes, Rio de Janeiro State, Brazil, and to identify these spaces in the urban environment in the district where the municipality is located. For the methodological development of the research, besides the bibliography on the subject, documentary research was conducted in the official journal of the municipality, semi-structured interviews with municipal managers, and data collection in field work. Among the results, it can be stated that there is a scarcity of green areas in Campos, and that most of these areas are located in the higher-income neighborhoods, which benefits the population with high socioeconomic status. It was also found that the public power has not been prioritizing the design of these spaces in view of the new socioeconomic dynamics, since they are lacking in the city.

Keywords: Green Areas; Public Investments; Social-Spatial Segregation.

\section{Filipe Garcia Teixeira}

Universidade Federal Fluminense, Instituto de Ciências da Sociedade e Desenvolvimento Regional. Graduado em Geografia e mestre em Desenvolvimento Regional, Ambiente e Políticas Públicas - UFF. Professor do Instituto Federal Fluminense. fgarcia.rox@gmail.com.

\section{Marco Antônio Sampaio Malagoli}

Universidade Federal Fluminense, Instituto de Ciências da Sociedade e Desenvolvimento Regional, professor do curso de Geografia e do Programa de Pós-Graduação em Desenvolvimento Regional, Ambiente e Políticas Públicas - UFF. Doutor em Psicologia Social - USP. marcomalagodi@id.uff.br. 


\section{Introdução}

0 presente trabalho parte da problematização a respeito da localização das áreas verdes públicas urbanas na cidade de Campos dos Goytacazes/RJ, e em que medida o poder público atua na criação e conservação desses espaços. Assim, para a estruturação metodológica da pesquisa, além da bibliografia especializada no tema, realizou-se pesquisa documental no Diário Oficial (D.O.) do município, trabalho de campo e entrevistas semiestruturadas com gestores municipais.

Para a construção do escopo teórico, buscou-se diversas fontes bibliográficas que trazem à lume 0 processo de valorização do solo urbano, tendo como pano de fundo o discurso ambiental e a implementação de elementos na cidade que exaltam a natureza, como parques, praças e jardins.

Alguns autores, como Serpa (2013), Henrique (2009) e Gomes (2009), evidenciam que a constituição de áreas verdes nas cidades contemporâneas, pautadas no discurso da sustentabilidade urbana e da qualidade de vida, se torna um instrumento que contribui para a valorização do solo, podendo intensificar o processo de especulação imobiliária de determinados bairros, principalmente aqueles ocupados pela população de alta renda. Assim, buscou-se trazer essas reflexões teóricas para a realidade do município de Campos, identificando e analisando em que medida os investimentos públicos em áreas verdes vêm se materializando no espaço urbano local frente às novas dinâmicas socioeconômicas.

0 município em questão vem passando por significativas transformações no seu espaço urbano, principalmente com a chegada do Porto do Açu e também pela dinamização da economia do petróleo. Esses dois fatores provocaram significativas transformações socioespaciais, as quais levaram a uma crescente dinamização do mercado imobiliário. Entre algumas mudanças observadas no espaço urbano campista, destacam-se: o aumento da verticalização urbana, principalmente em áreas mais valorizadas; 0 aumento de condomínios horizontais fechados de alto padrão; e a implementação de conjuntos habitacionais populares, como o Morar Feliz, que levou à remoção de uma parte significativa da população, a qual a prefeitura julgava viver em "áreas de risco".

Nesse sentido, na primeira parte do artigo, discutirse-á a cidade e a natureza no contexto capitalista contemporâneo e tecer-se-á uma crítica a respeito do termo "sustentabilidade". Na segunda parte, abordarse-á as transformações recentes no espaço urbano de Campos, principalmente as mudanças desencadeadas após a chegada do Porto do Açu. Já na terceira parte, apresentar-se-á as áreas verdes selecionadas, assim como os investimentos públicos realizados ao longo do período 2010-2018.

\section{A natureza e a cidade no contexto capitalista contemporâneo}

Nas cidades, a incorporação de espaços que remetem à natureza, como praças, parques, jardins e vias públicas arborizadas, é fortalecida pelas políticas de planejamento instituídas no espaço urbano a partir do século XIX. Já a contar da segunda metade do século XX, devido à crise ambiental e a toda a narrativa desenvolvida em prol do desenvolvimento sustentável, os espaços verdes urbanos passam a estar associados à proteção do meio ambiente e à melhoria da qualidade de vida dos citadinos.

Gomes (2009) ressalta que, principalmente desde a década de 1970 e, em especial, após a década de 1990, com a Rio 92, a natureza entrou no debate nacional e internacional e passou a ser focalizada pelas agendas governamentais e sociais. Logo, a presença de espaços livres vegetados, em especial a arbórea, se constituiu em um novo apelo de uma estratégia de viver "bem e melhor".

Rodrigues (2013) aponta que as questões propostas e discutidas durantea Confe rênciadas Nações Unidas sobre o Meio Ambiente e Desenvolvimento (CNUMAD), em 1992, culminaram na Agenda 211, na qual os países signatários se propunham a cumprir as metas estabelecidas durante o encontro. Porém, a autora, refletindo criticamente sobre esse acontecimento, destaca que tal documento se tornou uma suposta "salvação" para todos os males ambientais, desenvolvendo estudos em vários âmbitos, os quais referem-se ao "meio ambiente", ao "desenvolvimento sustentável" e às "sustentabilidades", "sem explicar a existência de um novo arcabouço teórico-metodológico e instrumentais analíticos que permitissem compreender os agentes, as contradições, os conflitos, as desigualdades e a segregação socioespacial em diferentes escalas" (RODRIGUES, 2013, p. 208).

Nesse sentido, a "natureza na cidade" entra no circuito da dinâmica capitalista eseus elementos, como praças arborizadas, parque e jardins, que se tornam objetos de valorização do solo, contribuindo para a especulação imobiliária. 
Nesse contexto, os agentes capitalistas se aproveitam da valorização simbólica da natureza e incorporam, nos seus discursos e práticas, a promoção de tecnologias verdes que se enquadram dentro dos pressupostos do conceito da "sustentabilidade". Acselrad (2009) aponta que o discurso da cidade sustentável está intimamente ligado à reprodução do capital. À medida que a cidade incorpora os valores sustentáveis, ela se torna atrativa para o capital e, consequentemente, para os investimentos imobiliários. Tornase sustentável para vendê-la. Assim, surge o pensamento único urbano: exige que as cidades se ajustem aos propósitos tidos por inelutáveis da globalização financeira (ACSELRAD, 2009).

Dessa forma, Gomes (2017) afirma que a "sustentabilidade" vem sendo concebida por agentes públicos e privados e sematerializa em ações como "disponibilização de áreas permeáveis, ampliação das áreas verdes e efetivo arbóreo, utilização de materiais biodegradáveis, coleta seletiva, etc." (GOMES, 2017, p. 14). Tais práticas, embora se constituam como elementos relevantes para o planejamento e gestão urbanos, acabam não alterando a questão da lógica da produção do espaço pautada na materialidade capitalista e na ampliação da segregação social. Logo, o autor infere que o discurso da sustentabilidade urbana mascara os verdadeiros interesses de certos agentes do capitalismo, pautados na competitividade interurbana e na projeção de gestões públicas.

Swyngedouw (2017), na mesma perspectiva de Gomes (2017), afirma que a questão da sustentabilidade tem sido "neoliberalizada" e se fundido com as ideias da modernização ecológica, que busca defender os benefícios econômicos da redução da poluição ambiental, e propõe uma utilização ecologicamente racional das operações administrativas dos recursos. Destarte, esse marco da sustentabilidade tem dado enfoque para questões mercadológicas e tecnocráticas, que buscam tornar 0 capitalismo "mais verde", ignorando, quase que na sua totalidade, os problemas inerentes à sociedade capitalista, como a ausência de justiça social e a intensificação das questões de inclusão e exclusão, que perpassam os ambientes urbanos (SWYNGEDOUW, 2017).

Para Lefebvre (2004), atribui-se a necessidade de espaços verdes nas cidades como se a presença da natureza fosse a salvação para os males, frutos da sociedade urbana industrial. Assim, essa "natureza" aparece associada aos lazeres, podendo ser "comprada" ou "vendida".

A definição de "natureza na cidade", que carrega um sentido ideológico, implica, portanto, a exclusão das classes economicamente inferiores do acesso à vida com a "natureza". Para os autores estudados, as classes subalternas não teriam direito à natureza na cidade, principalmente nos espaços enclausurados. Legitimase no mundo das ideias e do mercado a dominação ou manutenção de privilégios. Enquanto as classes dominantes vivem com a "natureza" artificializada e controlada em seus jardins, nos bairros dos excluídos observa-se a "natureza" relegada ao abandono ou, em muitos lugares, a total falta de qualquer "natureza" (HENRIQUE, 2009).

Pesquisas recentes de autores como Henrique (2009), Gomes (2009; 2017) e Serpa (2013) vêm mostrando que as grandes construtoras e incorporadoras imobiliárias se apropriam do discurso da natureza, com a finalidade de tornar seus empreendimentos mais atrativos para os consumidores. Conseguinte, partem da premissa de que a natureza presente nesses espaços ofereceria maior qualidade de vida para os habitantes urbanos, porém apenas para aqueles capazes de adquirir esses imóveis. Uma grande parcela da população continuaria apartada dessas benesses e, muitas vezes, estaria exposta a vários agravos ambientais em zonas de sacrifício (ACSELRAD, 2009). 


\section{A economia e a transformação do espaço urbano em Campos dos Goytacazes/ RJ}

A Região Norte Fluminense, onde o município de Campos está situado, teve sua economia assentada na produção sucroalcooleira durante muitas décadas, a qual tinha grande peso na economia local. Porém, desde o final dos anos 80, esse setor sofreu forte estagnação, o que gerou grande desemprego no município de Campos, que já chegou a ser o segundo maior produtor de cana do País (CRUZ, 2007). Essa forte decadência do setor agrícola foi compensada, posteriormente, pela renda advinda da exploração do petróleo. Embora o município de Campos não obtenha renda proveniente dos capitais fixos, na medida em que estes se concentram em sua maioria na faixa litorânea entre Maricá e Macaé, o mesmo obtém renda advinda dos repasses dos royalties (CRUZ, 2007). Dessa forma, criou-se uma dependência rentista que perdura até hoje.

Gomes (2015) aponta que o município de Campos, por estar inserido em uma das mais importantes bacias petrolíferas do País, vem apresentando forte dinamização econômica. Esse crescimento econômico teve um aumento mais acentuado a partir de meados dos anos 2000 e acabou atraindo a vinda de vários empreendimentos imobiliários e incorporadoras, que, junto ao poder público, passaram a orquestrar o crescimento do espaço urbano campista (ZACCHI, 2012).

No que tange ao espaço urbano campista, o Complexo Logístico e Industrial do Porto do Açu (CLIPA) também vem causando significativas transformações, principalmente no setor imobiliário, que ganhou ainda mais fôlego. Os empreendimentos imobiliários lançados no município são direcionados para diversos perfis socioeconômicos. Entretanto, os que mais se destacam são os apartamentos de elevado padrão e as casas em condomínios fechados (GOMES, 2015).

A verticalização é um dos fenômenos que vem alterando de forma significativa a paisagem urbana. Conforme observa-se na Figura 1, ela ocorre com maior frequência em certos bairros, como Centro, Parque Tamandaré,

MES T R A D 0

PESQUISA OPERACIONAL E INTELIGÊNCIA COMPUTACIONAL LINHA DE PESQUISA EM SAÚDE

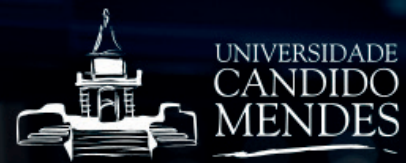


Parque Avenida Pelinca e Jardim Flamboyant. Percebese, no entanto, que a verticalização não ocorre em áreas periféricas da margem esquerda do rio (região de Guarus), onde se verifica a predominância de construções horizontais e residências unifamiliares. Para Freitas (2011), esses locais interessam pouco ao setor imobiliário, pois são ocupados em sua maioria pela população de baixa renda.

Figura 1: Edifícios acima de seis pavimentos, criados entre 2010 e 2018, nos bairros de Campos dos Goytacazes/RJ

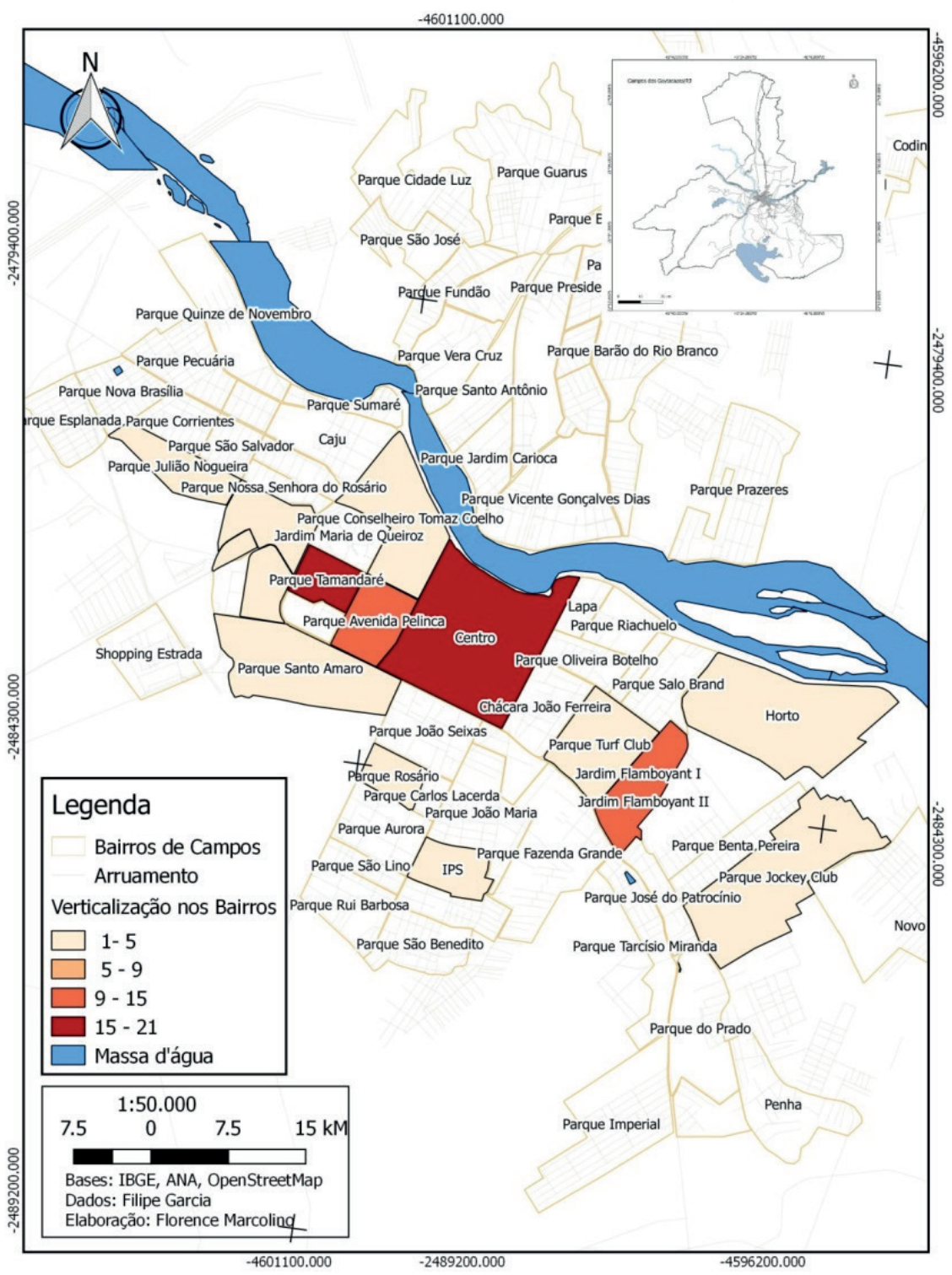

Fonte: Secretaria de Infraestrutura e Mobilidade Urbana de Campos dos Goytacazes. Dados: Filipe Garcia.

Elaboração: Florence Marcolino 
Durante o período mencionado, também pode-se observar em Campos a chegada de grandes empresas do ramo atacadista; grandes redes de supermercado, como 0 Walmart; lojas de varejo, como as Lojas Americanas, Marisa; e redes de fast food. Além disso, houve a inauguração do maior shopping da cidade (Boulevard Shopping), em 2011, que trouxe várias franquias, antes inexistentes, no espaço urbano local. Para Sposito (2007), essas questões dizem respeito à concentração de capitais no território, o que acaba provocando a expansão territorial das empresas comerciais de grande porte, nacionais ou transnacionais.

Porém, como ressalta Gomes (2015), embora as mudanças na base produtiva tenham desencadeado toda uma gama de transformações, como as citadas anteriormente, também foi notório 0 aumento dos problemas relacionados à oferta de habitação, transportes e serviços básicos de saúde e educação. Para Monié (2003) apud
Gomes (2015, p. 29), a urbanização de Campos é marcada por uma profunda segregação socioespacial, "na qual a paisagem urbana é caracterizada por uma oposição entre a cidade dos funcionários das grandes firmas e do resto da população que vive a jusante das atividades motrizes".

Nas áreas periféricas da cidade, o programa de habitação popular "Morar Feliz" teve um impacto significativo na vida das camadas urbanas de menor poder aquisitivo. Esse programa tinha como intuito remover famílias em situação vulnerável, residindo em moradias insalubres ou ocupando áreas ou regiões consideradas, pelo poder público, como "de risco" ou "áreas non edificant", e leválas para os conjuntos habitacionais. No entanto, tais conjuntos se situam em bairros distantes do centro e são desprovidos de qualquer serviço público, como hospitais, escolas etc., e de espaços públicos com áreas verdes.

\section{Figura 2: Casas do programa Morar Feliz da Prefeitura de Campos dos Goytacazes, localizadas no bairro Parque Eldorado}

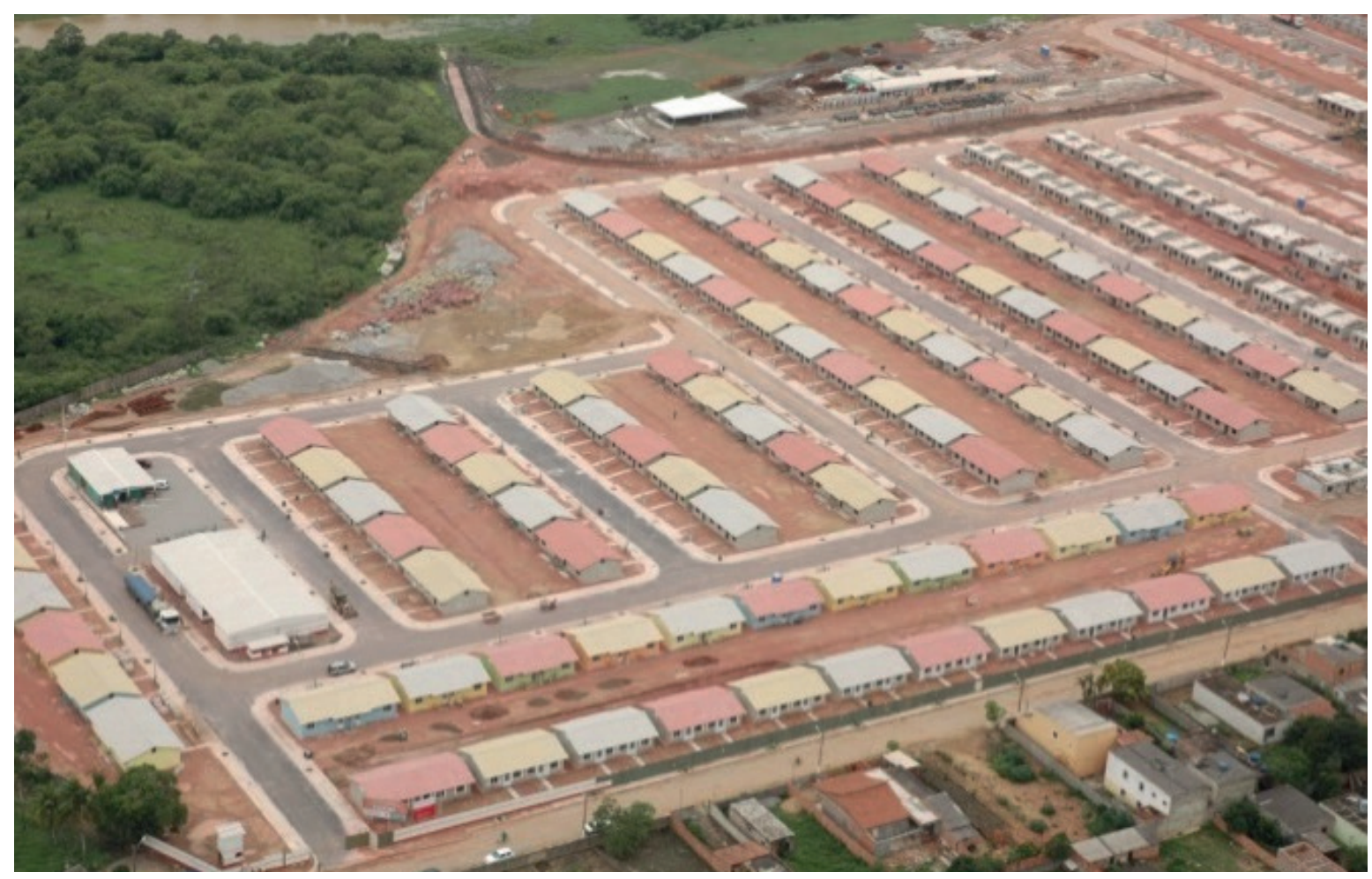

'Fonte: Extraído do site da Prefeitura de Campos dos Goytacazes 
Na Figura 2, pode-se observar um desses conjuntos habitacionais, sendo notória a ausência do "verde" nesses tipos de habitação popular. Essa questão reforça a ideia de Henrique (2009), o qual pontua que os atributos da natureza são apenas evidenciados para vender e valorizar imóveis de alto padrão localizados em bairros ou condomínios ocupados pela população de alta renda. A população pobre é levada a ocupar espaços com serviços públicos precários e, muitas vezes, sem a presença de qualquer "natureza".

\section{A seleção das áreas verdes}

Existem diferentes abordagens e conceitos a respeito da presença de vegetação na cidade. Portanto, considera-se importante destacar, nesta pesquisa, algumas concepções dos principais autores que versam sobre áreas verdes, e justificar a escolha metodológica ao optar-se por um desses conceitos. 0 ponto em comum observado entre as diferentes abordagens é o de que a vegetação deve ser o eixo estruturante presente nas áreas livres. Assim, toda área verde é uma área livre, porém o contrário não acontece, pois nem toda área livre é vegetada.

Para Loboda e De Angelis (2005), a qualidade de vida urbana está intimamente ligada a diversos fatores, como infraestrutura, desenvolvimento econômico-so- cial e aqueles ligados à questões ambientais. Logo, os autores concluem que as áreas verdes públicas se constituiriam em elementos imprescindíveis para o bem-estar da população, pois influenciariam na sua saúde física e mental (LOBODA \& DE ANGELIS, 2005).

Buccheri Filho e Nucci (2006) tecem as seguintes considerações a respeito do termo área verde:
Áreas verdes: são um tipo especial de espaços livres onde o elemento fundamental de composição é a vegetação. Elas devem satisfazer três objetivos principais: ecológico-ambiental, estético e de lazer. Vegetação e solo permeável (sem laje) devem ocupar, pelo menos, 70\% da área; devem servir à população, propiciando um uso e condições para recreação. Canteiros, pequenos jardins de ornamentação, rotatórias e arborização não podem ser considerados áreas verdes, mas sim "verde de acompanhamento viário", que com as calçadas (sem separação total em relação aos veículos) pertencem à categoria de espaços construídos ou espaços de integração urbana (BUCCHERI

FILHO \& NUCCI, 2006, p. 48).

MEST RA D 0

\section{PESQUISA OPERACIONAL E} INTELIGÊNCIA COMPUTACIONAL LINHA DE PESQUISA EM SAÚDE

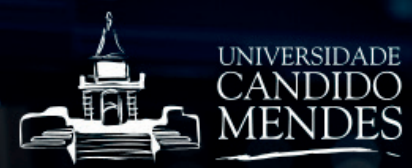


Dessa forma, a partir da interpretação desse conceito, três pontos se tornam cruciais no que concerne à importância das áreas verdes para o espaço urbano: a função ecológica/ ambiental, a funcionalidade estética e a função de lazer e recreação. Bartalini (1986) parte da mesma premissa afirmando que "as áreas verdes no meio urbano podem ser agrupadas em três conjuntos: o primeiro diz respeito aos valores visuais ou paisagísticos; o segundo aos valores recreativos e o terceiro aos valores ambientais" (BARTALINI, 1986, p. 49). Além disso, Buccheri Filho e Nucci (2006) contrapõem as concepções de Lima (1994) ao afirmarem que trechos de avenidas arborizadas, canteiros e rotatórias não podem ser considerados áreas verdes.

Com base na proposta de Cavalheiro et al. (1999), Buccheri e Nucci (2006) elaboraram um organograma de classificação para identificar os espaços livres públicos urbanos que podem exercer funções de áreas verdes. Para chegarem nessa classificação, os autores elaboraram cinco questionamentos listados a seguir:

1 - A vegetação é o elemento fundamental da composição?

2 - Cumpre funções: ecológicas, estéticas e de lazer?
3 - Área de 70\% de cobertura vegetal em solo permeável? (sem laje)?

\section{4 - Serve a população?}

5 - Propicia condições para recreação?

Se a resposta for positiva para essas questões, é possível considerar os sistemas públicos de espaços livres como "áreas verdes". Nesse sentido, a escolha metodológica, para se definir as áreas verdes do município de Campos, se baseou nos princípios adotados por Buccheri e Nucci (2006). Desta maneira, dentro dos parâmetros propostos e do escopo teórico selecionado, identificou-se as seguintes áreas verdes em Campos dos Goytacazes: Praça Barão do Rio Branco (Jardim do Liceu); Praça da República; Praça Nilo Peçanha (Jardim São Benedito); Parque Municipal Lagoa do Vigário; Horto Municipal; Praça dos Trovadores; e Praça Poeta Antônio Roberto Fernandes. A seguir, apresenta-se as imagens desses espaços:
Figura 3: Praça Barão do Rio Branco (Jardim do Liceu)

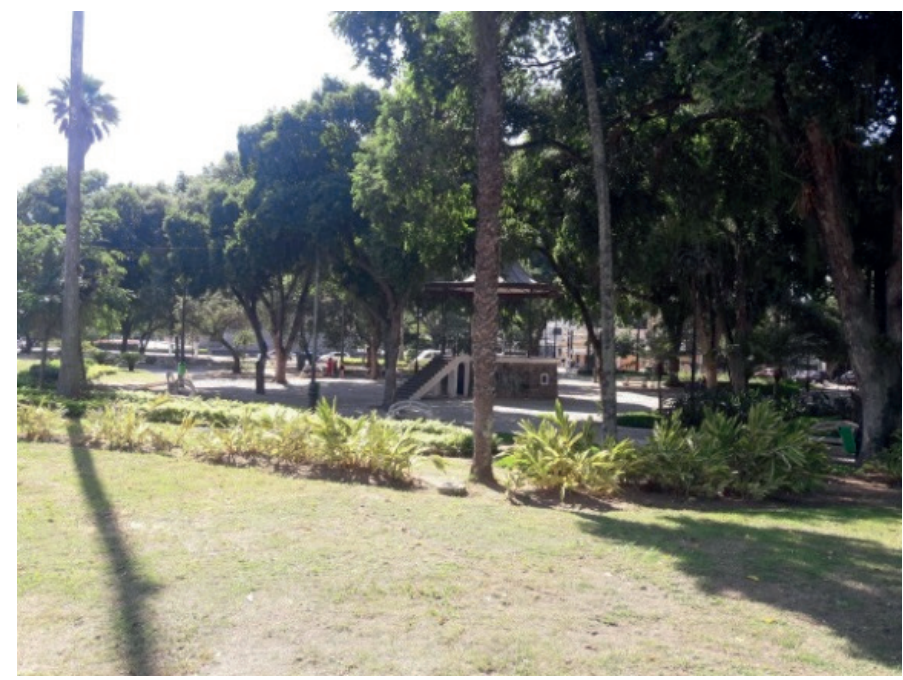

Fonte: Dados do autor (2019)
Figura 4: Praça da República

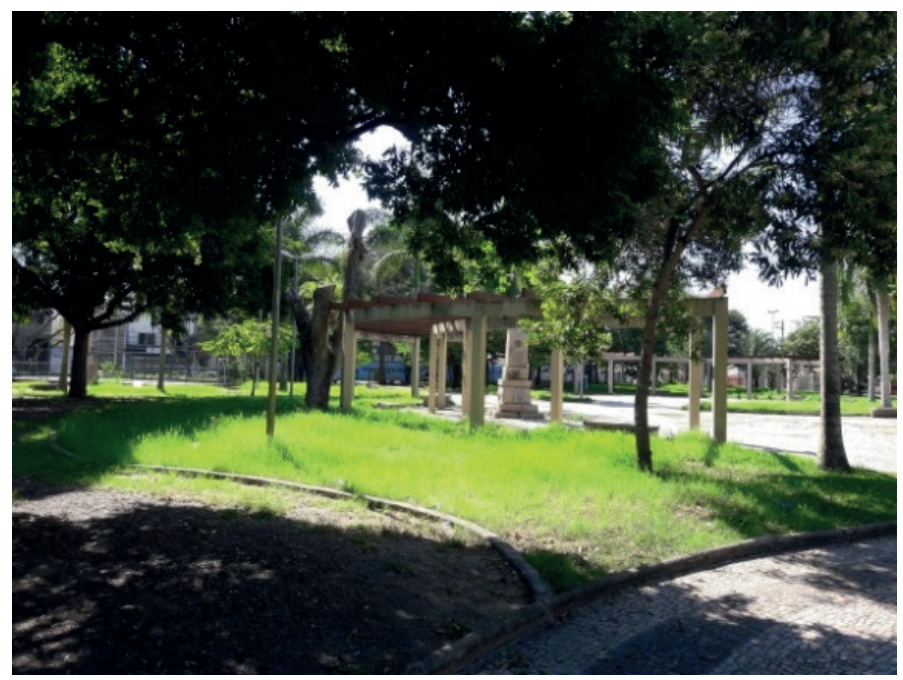

Fonte: Dados do autor (2019) 
Figura 5: Praça Nilo Peçanha (Jardim São Benedito)

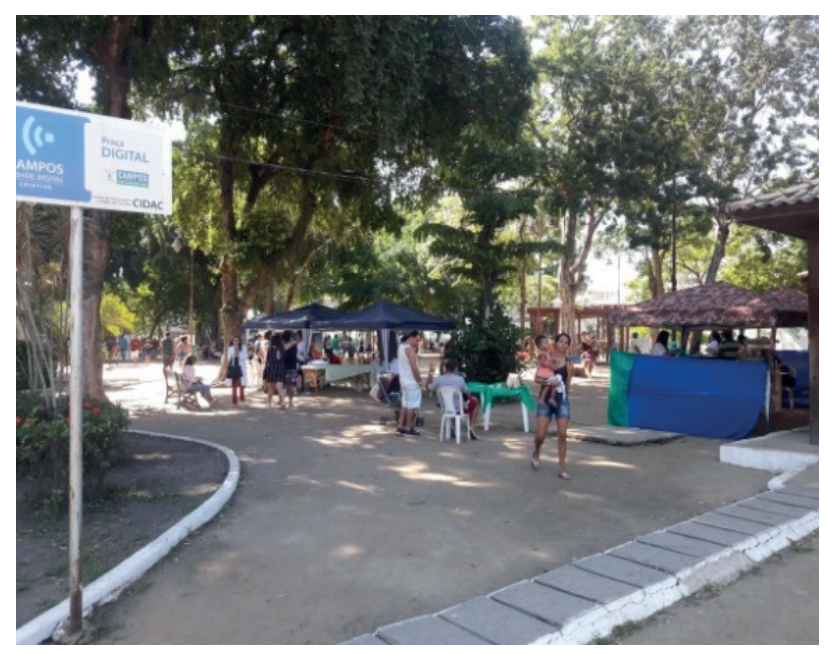

Fonte: Dados do autor (2019)

Figura 7: Horto Municipal

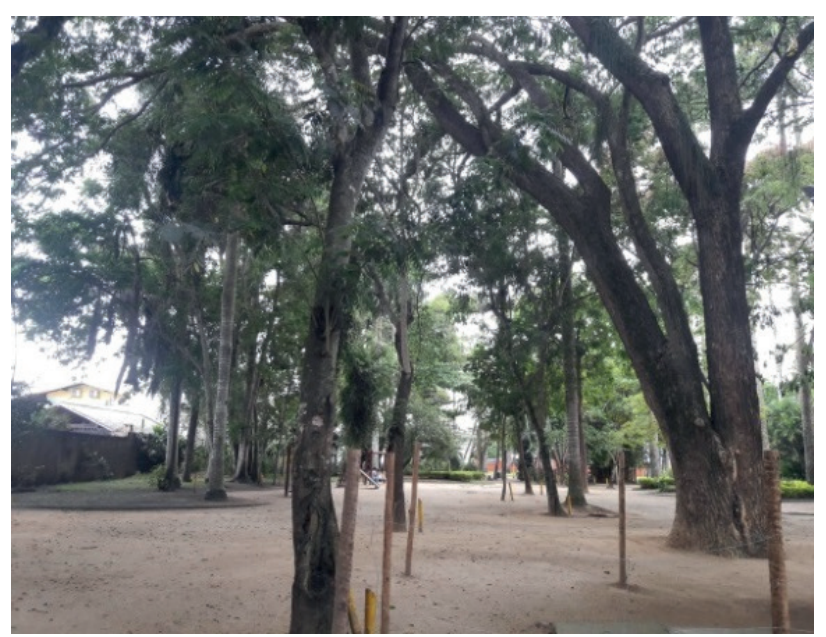

Fonte: Dados do autor (2019)
Figura 6: Parque Municipal Lagoa do Vigário

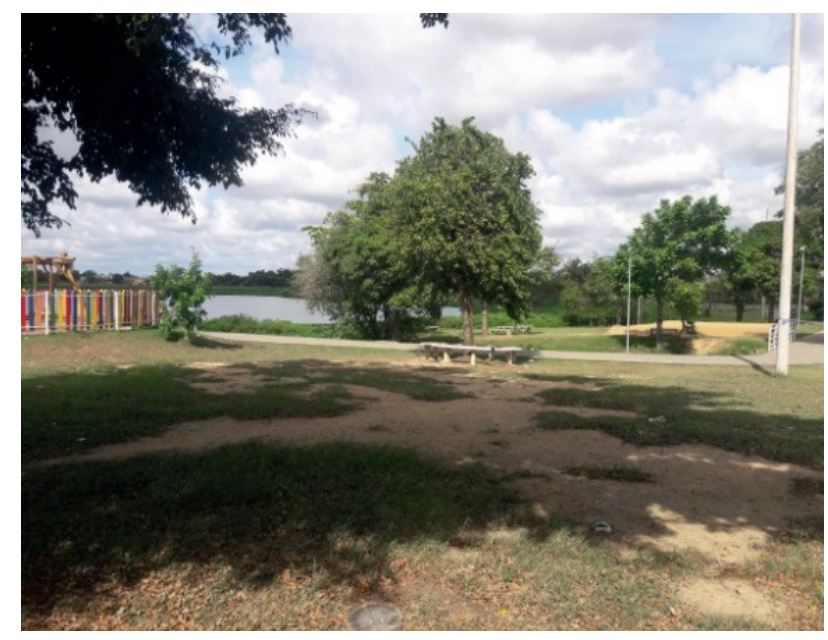

Fonte: Dados do autor (2019)

Figura 8: Praça dos Trovadores

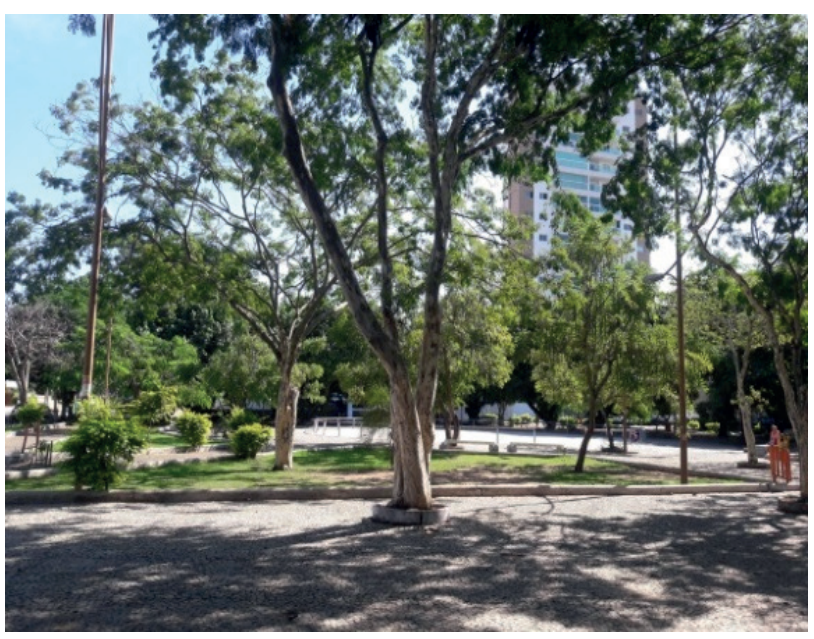

Fonte: Dados do autor (2019)

Figura 9: Praça Poeta Antônio Roberto Fernandes

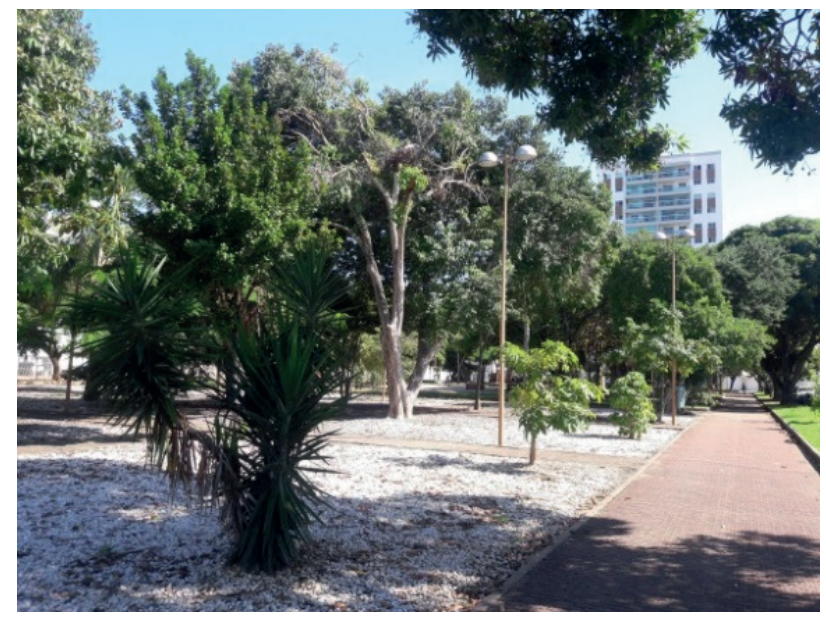

Fonte: Dados do autor (2019) 
Muitas praças presentes na cidade não foram consideradas áreas verdes neste trabalho, ora por apresentarem diversidade e quantidades arbóreas insuficientes, ora por estarem muito impermeabilizadas, não contribuindo, portanto, para o conforto ambiental e para a manutenção da biodiversidade. Abaixo, pode-se observar o mapa da área urbana de Campos e as áreas verdes urbanas selecionadas.
A partir da análise da Figura 10, constata-se que as áreas verdes delimitadas correspondem a um espaço bem reduzido da malha urbana do município, o que reforça a percepção da escassez desses espaços. Percebe-se que, na margem esquerda do Rio Paraíba do Sul, só existe uma área verde: 0 Parque Lagoa do Vigário.

Figura 10: Mapa de localização das áreas verdes em Campos dos Goytacazes

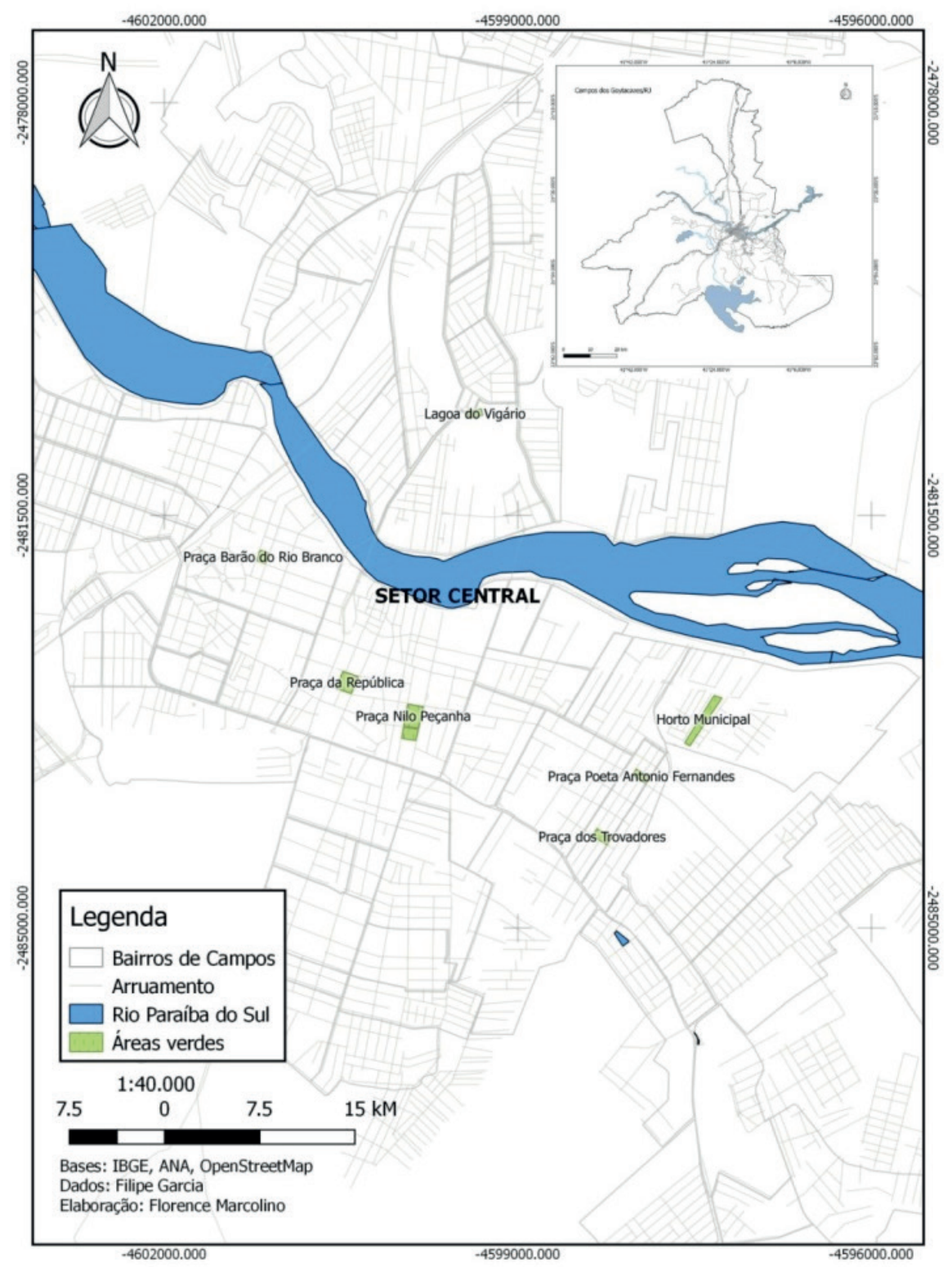

Dados: Filipe Garcia Teixeira. Elaboração: Florence Marcolino 


\section{Os investimentos públicos em áreas verdes e a problemática socioespacial}

Para se investigar os investimentos públicos em áreas verdes, foram coletados, no Diário Oficial da prefeitura, os dados referentes a esses gastos durante o período de 2010 a 2018. Com esta pesquisa, objetiva-se compreender a dinâmica da atuação do poder público, no que tange à aplicação de ações voltadas para a criação e a manutenção de áreas verdes.

A justificativa pela escolha do recorte temporal baseou-se em três premissas. A primeira se constitui no fato de que, com a chegada do Porto do Açu em 2007, o município passou por importantes transformações no espaço urbano, principalmente devido à chegada de grandes empreendimentos imobiliários. A segunda refere-se ao aumento expressivo dos royalties que a prefeitura passou a receber a partir de 2008, o que aumentou a arrecadação municipal e, consequentemente, influenciou nos gastos com obras públicas. 0 terceiro motivo tem a ver com o período em que 0 atual plano diretor esteve vigente (2008/2018). Assim, é importante verificar em que medida as políticas públicas, que estão na base normativa desse plano, foram contempladas no município no período em análise.

É necessário salientar que, no período em questão, o município de Campos passou por duas gestões distintas. De 2009 a 2016, a prefeitura esteve sob o comando da prefeita Rosângela Matheus, popularmente chamada de Rosinha. Já a partir de 2017, o prefeito Rafael Diniz assumiu a prefeitura e ainda encontra-se exercendo seu mandato.

A seguir, apresenta-se uma tabela com dados a respeito dos investimentos públicos em áreas verdes, obtidos a partir da consulta no Diário Oficial do município.

Tabela 1 - Investimentos públicos nas áreas verdes entre 2010/2018

$\begin{array}{lll}\text { Áreas Verdes } & \text { Bairros } & \text { Valor Gasto (R\$) } \\ \text { Praça da República } & \text { Centro } & 42.347,55 \\ \text { Praça Nilo Peçanha } & \text { Centro } & \text { Não consta } \\ \text { Praça Barão do Rio Branco } & \text { Jardim Maria Queiroz } & 136.626,69 \\ \text { Horto Municipal } & \text { Horto } & 153.497,44 \\ \text { Praça dos Trovadores } & \text { Jardim Flamboyant } & 38.152 \\ \text { Praça Poeta Antônio Fernandes } & \text { Jardim Flamboyant } & 106.203,08 \\ \text { Parque Lagoa do Vigário } & \text { Parque Gonçalves Dias } & \text { Não consta } \\ \text { Total } & & 406.826,76\end{array}$

Fonte: Diário Oficial do município. Organizado pelo autor. 
A partir dos dados acima, verifica-se que a área verde que recebeu mais investimento foi a do Horto Municipal, seguida pela Praça Barão do Rio Branco. É interessante observar que, quando selecionou-se apenas o valor gasto em áreas verdes - que foi de R\$ 406.826,76 - e comparou-se com o universo total de gastos, incluindo todas as praças e espaços de lazer - que foi de R\$13.722.513,81 -, os gastos em áreas verdes equivalem a $2,96 \%$ do valor total. Isso mostra que o poder público não realizou, no período selecionado, a expansão ou mesmo a implementação de novas áreas verdes na cidade.
Como comprovado a partir desta análise, utilizando um escopo teórico específico, o município de Campos possui poucas áreas verdes, sendo que a maioria delas se localiza no setor central. Apenas o Parque Lagoa do Vigário situase no setor norte, no Bairro Parque Gonçalves Dias. Quando compara-se as áreas verdes e os dados socioespaciais, temse a seguinte configuração:

Figura 10: Mapa de localização das áreas verdes em Campos dos Goytacazes

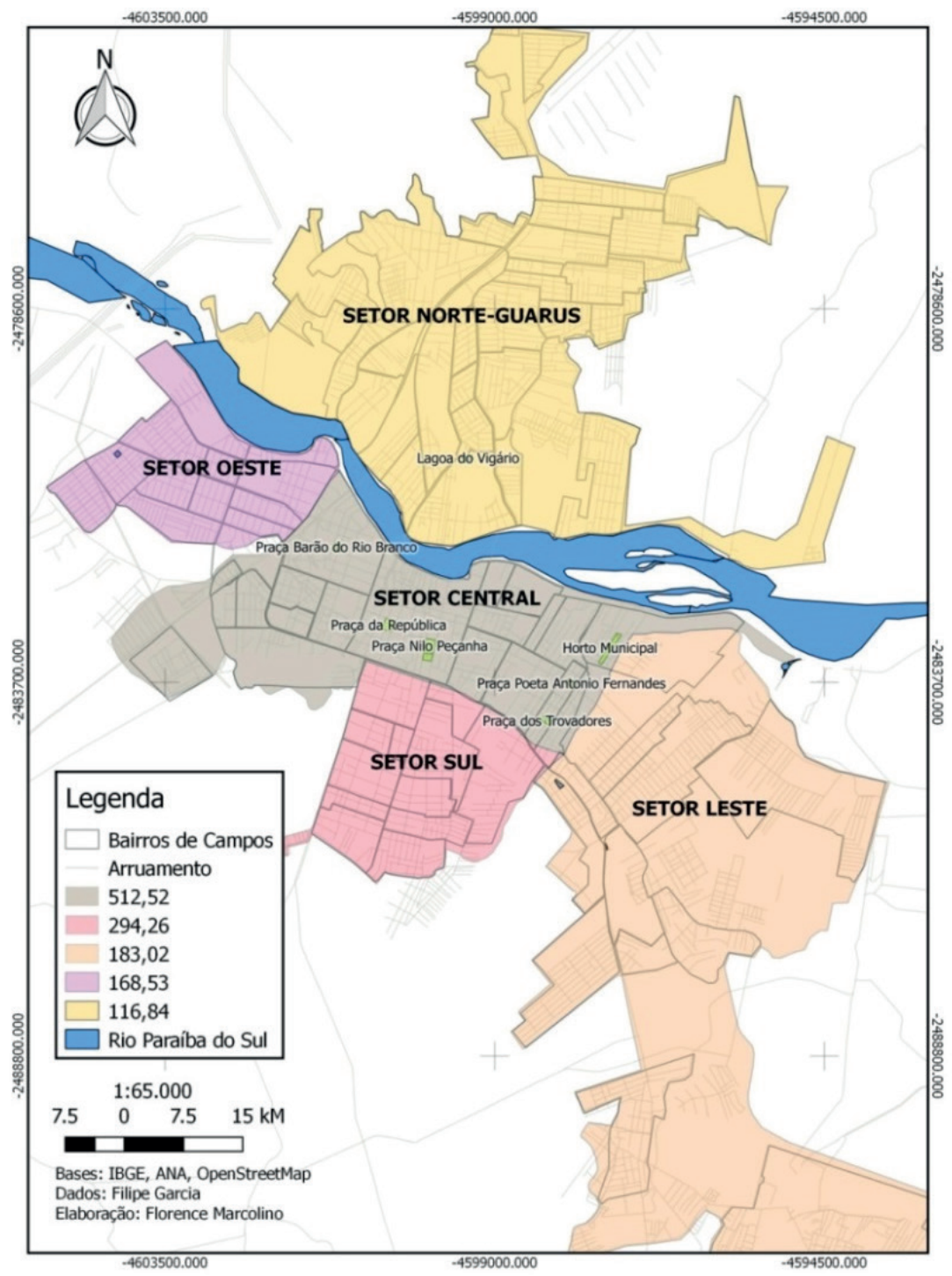

Dados: Gomes (2015). Elaboração: Florence Marcolino. 
Como pode-se constatar na Figura 11, o setor central é responsável pelo maior valor do solo, sendo também onde se concentram as áreas verdes. Esse setor apresenta os bairros de maior verticalização, como o Parque Avenida Pelinca e o Parque Tamandaré. 0 Jardim Flamboyant também é um importante eixo de verticalização, que, como observa-se na Figura, possui duas áreas verdes.

Tabela 2 - Áreas verdes e dados socioespaciais

\begin{tabular}{|c|c|c|c|}
\hline Área Verde & Bairro & $\begin{array}{c}\text { Renda } \\
\text { domiciliar } \\
\text { (R\$) }\end{array}$ & Setor \\
\hline
\end{tabular}

$\begin{array}{lllll}\text { Praça dos Trovadores/Poeta Fernando } & \text { Jardim Flamboyant } & 1.876,00 & \text { Central } & 417,67 \\ \text { Praça Nilo Peçanha } & \text { Centro } & 1.626,00 & \text { Central } & 395,25\end{array}$

Praça da República

Praça Barão do Rio Branco

Horto Municipal

Parque Lagoa do Vigário

Fonte: IBGE, 2018; Gomes (2015). Organizado pelo autor.
Centro

Jardim Maria Queiroz

Horto

Parque Gonçalves Dias

588,00

$2.219,00$

Central

695,08

1.626,00 Central 395,25

$1.281,00$

Central

515,52

Norte

116,84
A QUALIDADE DE ENSINO QUE VOCE JÁ CONHECE.
INSCREVA-SE AGORA!

口 PRESENCIAL

口 SEMIPRESENCIAL

口 EAD

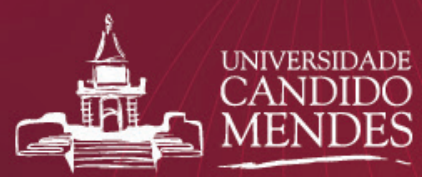


Como pode-se perceber na Tabela 2, os valores do solo se apresentam bem maiores na área central do que no setor norte, no bairro Parque Gonçalves Dias (região de Guarus), onde se localiza o Parque Lagoa do Vigário. 0 bairro que possui maior valor do solo, entre os que possuem área verde, é o bairro Jardim Maria Queiroz, seguido pelo Jardim Flam- boyant. Também observa-se que as áreas verdes se localizam predominantemente nos bairros que possuem maior renda mensal por domicílio. A exceção é o Parque Lagoa do Vigário, que se localiza em um bairro de menor renda.

Tabela 3 - Bairros que possuem áreas verdes e suas respectivas populações

Bairros População

Centro

10.071

Jardim Maria Queiroz

1.690

Horto

3.218

Flamboyant

1.506

Parque Guarus

3.761

Total

20.246

\section{A QUALIDADE DE ENSINO QUE VOCE JÁ CONHECE.}

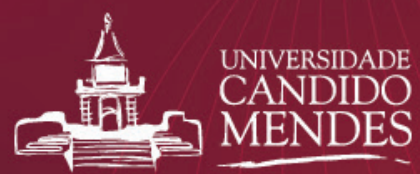


Analisando-se os dados da Tabela 3, chama-se a atenção para o fato de apenas uma pequena parcela da população campista ter espaços verdes em seus bairros. Assim, a população urbana de Campos, que está em torno de 418.565 habitantes (IBGE, 2010), fica, em sua maior parte, desassistida no que se refere à presença de áreas verdes.

Portanto, pode-se afirmar, a partir dos dados apresentados e analisados, que as áreas verdes na cidade estão concentradas no setor central, o que dificulta o acesso de grande parte da população a elas. Aliado a isso, a precariedade do transporte público também é um fator que tende a agravar a situação. Igualmente, foi constatado que os bairros que as possuem são os que apresentam maior valor do solo e maior média de renda domiciliar. Além disso, é possível afirmar que a cidade como um todo carece de áreas verdes de uso público, que são de grande importância no espaço urbano devido aos benefícios socioambientais que apresentam.

No decorrer das pesquisas, constata-se que a prefeitura não publica diariamente em D.O. os valores gastos com a manutenção, conservação e limpeza das praças e áreas verdes. Porém, no dia 16 de junho de 2016, ainda no governo da prefeita Rosinha, a prefeitura emitiu uma nota no Diário Oficial, na qual constava a contratação de uma empresa para cuidar das áreas verdes urbanas. No contrato, a prefeitura destacou que a manutenção se daria em "praças, parques, jardins e afıns". A empresa contratada foi a Emec Obras e Serviços Ltda., que recebeu a vultosa quantia de RS 11.450.000,00 (onze milhões, quatrocentos e cinquenta mil reais). Tal valor equivale à quantia de quase um milhão de reais por mês. Esse foi o único gasto publicado, referente à conservação desses espaços. Logo, devido essa insuficiência de dados, levou-se a entrevistar dois gestores: o Subsecretário de Infraestrutura e Mobilidade Urbana e o Superintendente de Limpeza Pública.
Na entrevista com o Secretário de Infraestrutura e Mobilidade Urbana, foi questionado quem realiza o trabalho de manutenção e conservação das praças e áreas verdes. Ele informou que, até 2016 (governo Rosinha), quem realizava o serviço de limpeza e ornamentação das praças era a empresa Emec (a que recebeu 11 milhões). Segundo o subsecretário, essa empresa era especializada em questões paisagísticas e tinha muito cuidado com a ornamentação e embelezamento de vários espaços ajardinados da cidade, como canteiros centrais, trevos, rotatórias e praças. Porém, ele destacou que, com a diminuição da arrecadação dos royalties e a consequente crise orçamentária, o contrato com essa empresa foi desfeito e a empresa Vital, que atuava apenas na limpeza pública e coleta de lixo, passou a atuar, também, na conservação das praças e outros espaços ajardinados. Contudo, consequentemente, essas áreas perderam em qualidade de embelezamento e ornamentação. Entretanto, o subsecretário não soube informar o valor gasto pela Emec em cada bairro para a manutenção das áreas. Ele também não soube informar a respeito dos contratos com a empresa Vital e como é realizada a limpeza das praças e áreas verdes.

A fim de obter respostas para esses questionamentos, marcou-se uma entrevista com o Superintendente de Limpeza Pública, quem destacou que o trabalho realizado pela empresa Vital inclui a poda de árvores, corte de grama e a própria limpeza. Segundo ele, o trabalho de limpeza (varrição e coleta de lixo) é feito com frequência em todas as praças da área central. Nas praças periféricas, a limpeza é feita três vezes por semana, assim como a coleta de lixo nas residências. Porém, segundo ele, a manutenção do gramado e a poda das árvores, assim como o trabalho paisagístico, são feitas a cada dois meses.

\section{A QUALIDADE DE ENSINO QUE VOCE JÁ CONHECE.}

INSCREVA-SE AGORA!

口 PRESENCIAL

口 SEMIPRESENCIAL

口 EAD

www.ucam-campos.br

22 2726-2400 
Questionado sobre esse longo intervalo de tempo, ele destacou que a cidade possui muitas praças e que a empresa não possui funcionários suficientes para dar conta de fazer todo o trabalho com frequência. Ressaltou, no entanto, que, quando as praças apresentam fortes sinais de deterioração, como mato muito alto e árvores ameaçando a rede elétrica ou a integridade dos usuários, a prefeitura encaminha uma equipe responsável para a execução desses serviços. Destacou que, no período quente e chuvoso, esse trabalho é feito com mais frequência, devido ao rápido crescimento do conjunto vegetal.

Ademais, questionado sobre os valores gastos com a manutenção das praças, também destacou, assim como o fez o Subsecretário de Mobilidade Urbana, que a crise orçamentária pela qual a prefeitura vem passando limitou os gastos do poder público em demasia. 0 Superintendente relatou que, quando o atual governo assumiu a prefeitura em 2017, o contrato com a empresa Vital ultrapassava os oito milhões. Com o decorrer do tempo, esse valor foi reduzido, com a finalidade de cortar gastos excessivos, fazendo o contrato cair para patamares de três milhões. Atualmente, foi mencionado que o contrato com a empresa Vital se encontra na faixa de seis milhões, o que foi possível devido a uma sensível melhora da arrecadação municipal. Logo abaixo, apresenta-se um gráfico (Figura 12) que mostra a arrecadação de royalties e participações especiais em Campos.

A partir da leitura da Figura 12, pode-se inferir que a arrecadação que vinha aumentando desde 2010, mantendo-se em patamares de mais de um bilhão até 2014, sofreu uma queda abrupta em 2015, chegando no ápice da redução em

Figura 12: Evolução dos royalties e participações especiais: 2010-2018

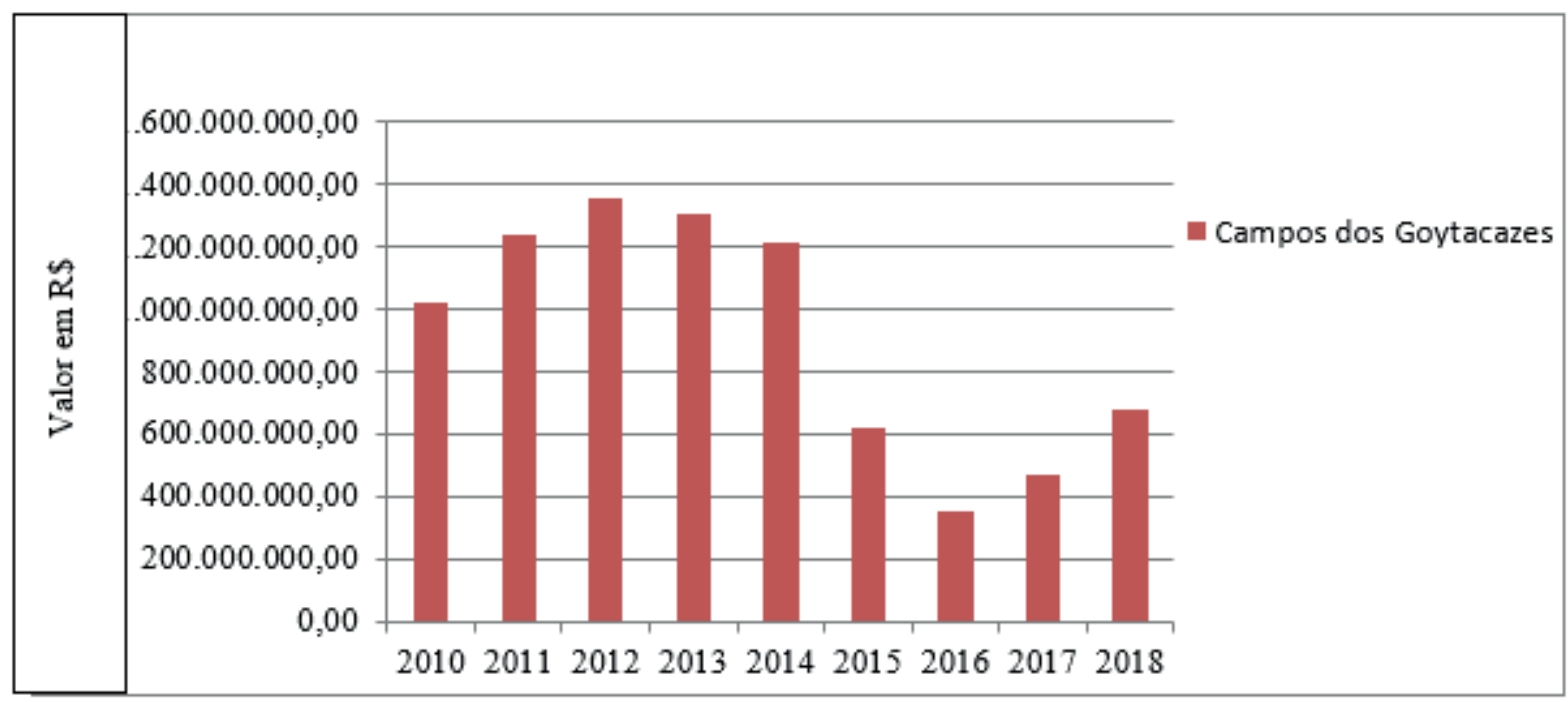

Fonte: Inforoyalties

2016. Os dados apresentados confirmam, nesse sentido, a fala dos agentes públicos, quando mencionam a crise orçamentária do município devido à diminuição da arrecadação de royalties. Porém, a partir de 2017, a arrecadação vem melhorando gradativamente, pois o barril de petróleo vem apresentando contínua valorização.

Nas entrevistas, foi relatado pelos agentes públicos dessa gestão que a limpeza acontece de forma mais frequente nas praças mais centrais, que são mais frequentadas. Quem decide sobre a frequência de limpeza é a própria empresa Vital, que também tem autonomia para aplicar o dinheiro recebido. Essas questões dificultaram ter uma visão mais detalhada a respeito dos valores gastos em cada espaço individualmente.
Segundo Vasconcelos (2013), a degradação do espaço público nas cidades brasileiras se deve à ausência de políticas públicas para cuidar da paisagem urbana. Para o autor, essa degradação tende a ser mais acelerada em áreas habitadas por grupos de menor renda, e quanto pior a qualidade estética do espaço público, pior tende a ser a qualidade de vida. 


\section{Considerações Finais}

À guisa da pesquisa realizada e analisada ao longo deste trabalho, considera-se que as áreas verdes no município de Campos apresentam-se insuficientes no tecido urbano e tendem a concentrar-se em determinadas áreas específicas - principalmente na área central -, não atendendo, assim, à cidade de forma geral. Além disso, foi possível constatar que a prefeitura não realizou a criação de nenhuma área verde no período selecionado, o que se leva a concluir que o poder público, atualmente, não vem priorizando a criação desses espaços frente às novas dinâmicas e transformações socioeconômicas.

Percebeu-se que a arrecadação de royalties exerce um papel importante na manutenção e conservação de praças e jardins, uma vez que os agentes públicos alegaram que a diminuição desses repasses incidiu diretamente na sua piora da qualidade. Porém, é necessário salientar que a criação de espaços públicos vegetados é de suma importância para a constituição de uma cidade mais aprazível e sustentável, visto os benefícios que esses espaços proporcionam.
É possível afırmar que a insuficiência de áreas verdes no espaço urbano pode favorecer a declaração dos condomínios privados que reforçam o discurso exclusivista das áreas verdes e de lazer. Isso resulta em uma cidade ainda mais segredada e excludente, pois tende a promover um pensamento individualista: aqueles que desejam ter acesso a um ambiente mais aprazível, mais "verde", com mais qualidade de vida, devem ocupar áreas privadas, fortificadas, como os condomínios fechados. No entanto, esses espaços só são acessíveis a uma parcela restrita da população.

É de suma importância, nesse sentido, que os trabalhos acadêmicos continuem acompanhando os desdobramentos das políticas ambientais urbanas no município, a fim de desvendar e decodificar os diferentes interesses que passam por essa temática. No contexto capitalista atual, em que a cidade está inserida na lógica "neoliberalizada" (SWYNGEDOUW, 2017), é preciso estar atento às ações do Estado e verificar, de fato, se elas priorizam políticas de inclusão e democratização dos espaços públicos ou se atendem apenas a interesses econômicos, os quais acabam provocando mais segregação e desigualdades.

M E S T R A D 0 
ACSELRAD, H. Sentidos da sustentabilidade urbana. In: ACSELRAD, H. (org.) A duração das cidades: Sustentabilidade e risco nas políticas urbanas. Rio de Janeiro: Lamparina, 2009. cap 1. p.43-70.

BARTALINI, V. Áreas verdes e espaços livres urbanos: paisagem e ambiente. Edusp: São Paulo, 1986.

CRUZ, J. L. V. Os desafios do Norte e do Noroeste Fluminenses frente aos grandes projetos estratégicos. Vértices, Campos dos Goytacazes, v. 9 , n. 1-3, p. 43-50, 2007.

BUCCHERI FILHO, A.T.; NUCCI, J. C. Espaços Livres, Áreas Verdes e Cobertura Vegetal no Bairro Alto da XV, Curitiba - PR. Revista do Departamento de Geografia, São Paulo, v. 18, p. 48-59, 2006.

FALCÃO, D. A. À espera de Morar Feliz: entre a remoção e o reassentamento do programa habitacional Morar Feliz, um território da espera. 2011. 111 f. Dissertação (Mestrado em Políticas Sociais) - Universidade Estadual do Norte Fluminense, Campos dos Goytacazes, RJ, 2011.

MENDES, J. T. N.; GOMES, M. A. S.; SIQUEIRA, A. M. M. Políticas públicas, moradia popular e o Programa Morar Feliz em Campos dos Goytacazes-RJ: uma análise acerca da favela Margem da Linha. Revista Libertas, Juiz de Fora, v.14, n.1, p. 37-56, 2014.

GOMES, M. A. S. Parques Urbanos de Ribeirão Preto-SP: na produção do espaço, o espetáculo da natureza. 2009. 317 f. Tese (Doutorado em Geografia) - Universidade Estadual de Campinas, Campinas, SP, 2009.

GOMES, M. A. S. A produção e a valorização desigual do espaço urbano em Campos dos Goytacazes-RJ: uma análise das ações do estado e dos promotores/incorporadores imobiliários. Geografares, Vitória, p. 28-41, jan.-jul., 2015.

GOMES, M. A. S. Análise dos critérios técnicos "indicadores de sustentabilidade" em projetos de grandes parques urbanos (Rio de Janeiro/ Brasil e Lisboa/Portugal). 2017. 105 f. Relatório (Estágio de Pós-Doutoramento) - Universidade Federal do Rio de Janeiro, Rio de Janeiro, RJ, 2017.

HARVEY, D. A produção capitalista do espaço. São Paulo: Annablume, 2005.

HENRIQUE, W. 0 direito à natureza na cidade. Salvador: EDUFBA, 2009. 186p.

IBGE - Instituto Brasileiro de Geografia e Estatística. Disponível em: http://www.cidades.ibge.gov.br/xtras/perfil.php?lang=\&codmun=330100\&search=rio-de-janeiro|campos-dos-goytacazes. Acesso: 05 abr 2019

INFOROYALTIES. Disponível em < https://inforoyalties.ucam-campos.br/informativo.php> Acesso em 22 maio 2019.

LEFÈBVRE, H. 0 direito à cidade. 3 ed. São Paulo: Centauro, 2004.

LOBODA, C. R.; DE ANGELIS, B. L. D. Áreas verdes públicas urbanas: conceitos usos e funções. Ambiência: Revista do Centro de Ciências Agrárias e Ambientais, Guarapuava, Paraná, v. 1, n. 1, p. 125-139, jun. 2005.

RODRIGUES, A. M. A matriz discursiva sobre o "Meio Ambiente”: produção do espaço urbano - agentes, escalas, conflitos. In: CARLOS, A. F. A. et al. (orgs.) A produção do espaço urbano: agentes e processos, escalas e desafios. São Paulo: Contexto, 2013. cap 11. p.207-230.

SERPA, A. 0 espaço público na cidade contemporânea. 2. ed. São Paulo: Contexto, 2013. 205 p.

SWYNGEDOUW, E. Cidades, coesão social e o meio ambiente: justiça urbana ambiental ou ecologia política? In: CASTRO, J. E. et al. (Orgs) Tensão entre justiça ambiental e justiça social na América Latina: o caso da gestão da água. Campina Grande: EDUEPB, 2017. cap 2. p.67-113.

SPOSITO, M. E. B. Cidades médias: reestruturação das cidades e reestruturação urbana. In: SPOSITO, M. E. B. (org.) Cidades Médias: espaços em transição. São Paulo: Expressão Popular, 2007.

VASCONCELOS, P.; CORRÊA, R. L.; PINTAUDI, S. (orgs.) A cidade contemporânea: segregação espacial. São Paulo: Contexto, 2013. p. 15-93.

ZACCHI, R. C. 0 papel dos proprietários fundiários e do estado no processo de conversão de terras rurais em urbanas e na produção de loteamentos fechados: Campos dos Goytacazes/ RJ (1980-2011). 2012. 170f. Dissertação (Mestrado em Políticas Sociais) - Universidade Estadual do Norte Fluminense, Campos dos Goytacazes, RJ, 2012.

A Agenda 21 se constituiu em uma carta de intenções, cujos países signatários se comprometeram a desenvolver ações em diversas áreas de atuação, com a suposta pretensão de implementar o "desenvolvimento sustentável".

0 termo "desenvolvimento sustentável", instituído na Comissão Brundtland das Nações Unidas, em 1987, se constitui "naquele que atende às necessidades do presente sem comprometer a possibilidade de as gerações futuras atenderem às suas próprias necessidades" (GOMES, 2017, p. 20). 